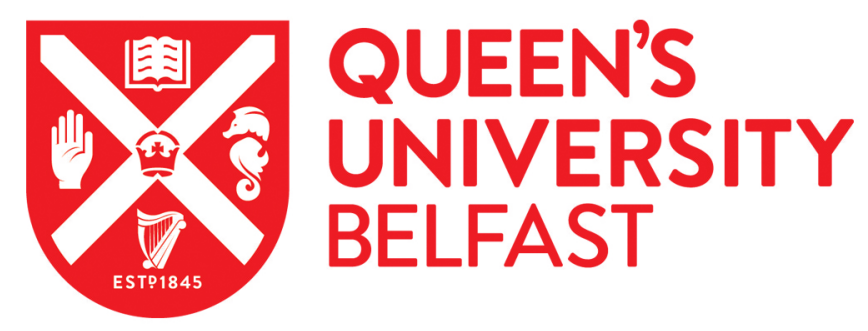

\title{
Exploring the needs, concerns and knowledge of women diagnosed with gestational diabetes: A qualitative study
}

Draffin, C. R., Alderdice, F. A., McCance, D. R., Maresh, M., Harper, R., McSorley, O., \& Holmes, V. A. (2016). Exploring the needs, concerns and knowledge of women diagnosed with gestational diabetes: A qualitative study. Midwifery: an international journal. https://doi.org/10.1016/j.midw.2016.06.019

\section{Published in:}

Midwifery: an international journal

\section{Document Version:}

Peer reviewed version

Queen's University Belfast - Research Portal:

Link to publication record in Queen's University Belfast Research Portal

\section{Publisher rights}

(c) Elsevier Ltd. This manuscript version is made available under the CC-BY-NC-ND 4.0 license http://creativecommons.org/licenses/by-nc$\mathrm{nd} / 4.0 /$ which permits distribution and reproduction for non-commercial purposes, provided the author and source are cited.

\section{General rights}

Copyright for the publications made accessible via the Queen's University Belfast Research Portal is retained by the author(s) and / or other copyright owners and it is a condition of accessing these publications that users recognise and abide by the legal requirements associated with these rights.

Take down policy

The Research Portal is Queen's institutional repository that provides access to Queen's research output. Every effort has been made to ensure that content in the Research Portal does not infringe any person's rights, or applicable UK laws. If you discover content in the Research Portal that you believe breaches copyright or violates any law, please contact openaccess@qub.ac.uk. 


\section{Author's Accepted Manuscript}

Exploring the needs, concerns and knowledge of women diagnosed with gestational diabetes: A qualitative study

C.R. Draffin, F.A. Alderdice, D.R. McCance, M. Maresh, R. Harper, O. McSorley, V.A. Holmes

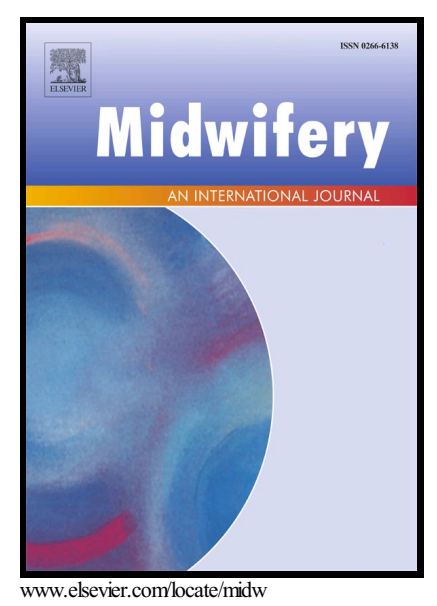

PII: $\quad$ S0266-6138(16)30108-5

DOI: $\quad$ http://dx.doi.org/10.1016/j.midw.2016.06.019

Reference: $\quad$ YMIDW1890

To appear in: Midwifery

Received date: 8 January 2016

Revised date: 22 June 2016

Accepted date: 24 June 2016

Cite this article as: C.R. Draffin, F.A. Alderdice, D.R. McCance, M. Maresh, R Harper, O. McSorley and V.A. Holmes, Exploring the needs, concerns anc knowledge of women diagnosed with gestational diabetes: A qualitative study Midwifery, http://dx.doi.org/10.1016/j.midw.2016.06.019

This is a PDF file of an unedited manuscript that has been accepted fo publication. As a service to our customers we are providing this early version o the manuscript. The manuscript will undergo copyediting, typesetting, an review of the resulting galley proof before it is published in its final citable form Please note that during the production process errors may be discovered whic could affect the content, and all legal disclaimers that apply to the journal pertain 


\section{ACCEPTED MANUSCRIPT}

Full Title: Exploring the needs, concerns and knowledge of women diagnosed with gestational diabetes: A qualitative study.

Running Head: Exploring the needs, concerns and knowledge of women diagnosed with gestational diabetes: A qualitative study.

Authors:, CR Draffin, ${ }^{\mathrm{a}}$ FA Alderdice, ${ }^{\mathrm{b}}$ DR McCance, ${ }^{\mathrm{c}}$ M Maresh, ${ }^{\mathrm{d}}$ R Harper, ${ }^{\mathrm{e}}$ O McSorley, ${ }^{\mathrm{a}}$ and VA Holmes ${ }^{\mathrm{a}}$

${ }^{\text {a }}$ Centre for Public Health, School of Medicine, Dentistry and Biomedical Sciences, Queen's University Belfast, Belfast, UK;

${ }^{\mathrm{b}}$ School of Nursing and Midwifery, Queen's University Belfast, Belfast, UK;

${ }^{\mathrm{c}}$ Regional Centre for Endocrinology and Diabetes, Royal Victoria Hospital, Belfast, UK

d St Mary's Hospital, Central Manchester University Hospitals NHS FT, Manchester Academic Health Sciences Centre.

${ }^{\mathrm{e}}$ Ulster Hospital, South Eastern Health and Social Care Trust, Dundonald, UK;

\section{Corresponding Author:}

Dr Valerie Holmes

Centre for Public Health, School of Medicine, Dentistry and Biomedical Sciences, Queen's University Belfast, Belfast BT12 6BA, UK

Phone: 02890634245 Email: v.holmes@qub.ac.uk

\section{Introduction}




\section{ACCEPTED MANUSCRIPT}

Gestational diabetes mellitus (GDM) prevalence rates have increased in recent years, varying from 4.6-9.2\% in the USA (DeSisto et al.2014) and from 1-28\% in other developed countries (Jiwani et al.2012). This variation is at least dependent on the lack of uniformity in relation to diagnostic criteria utilised in recent years, number of women screened, rates of obesity and the ethnicity and background rates of type 2 diabetes within the general population (DeSisto et al.2014, Jiwani et al.2012). Women with GDM have a 7-fold risk of developing type 2 diabetes in later life compared to women who are normoglycaemic in pregnancy (Bellamy et al.2009).

Diagnosis of Gestational diabetes mellitus (GDM) is usually made according to blood glucose levels following an oral glucose tolerance test (OGTT). In 2010 the International Association of the Diabetes in Pregnancy Study Groups (IADPSG) recommended a new diagnostic criteria which uses lower glucose cut-off thresholds used to diagnose women with GDM (Metzger et al. 2010). Much debate has followed as recommended changes to diagnostic criteria will impact on the workload for the multidisciplinary diabetes care team by an estimated 22-32\%, in settings which are already overstretched (Flack et al.2010).

Women diagnosed with GDM face a steep learning curve, in terms of adapting to their new diagnosis (Tait Neufeld, 2011, Daniells et al.2003, Persson et al. 2010 \& Tait Neufeld, 2014).To date, research has focused on the diagnostic thresholds, treatment of the condition and pregnancy outcome. By contrast little is known about the knowledge, concerns, psychological needs and barriers to adopting a healthier lifestyle among women diagnosed with GDM. Previous research has shown that women feel frustrated by the condition (Tait Neufeld, 2011, Persson et al. 2010 \& Razee et al.2010) and feel a lack of control (Persson et al.2010, Razee et al.2010 \& Evans \& O’Brien 2005). Others have reported that dietary advice is not specific or individualised, or in general is complex and difficult to adhere to (Tait Neufeld, 2011, Razee et al.2010 \& Bandyopadhyay et al.2011). 


\section{ACCEPTED MANUSCRIPT}

An increased knowledge of the needs and concerns of women with GDM would provide the multidisciplinary diabetes care team and other health care professionals (HCP's), including midwives, with a better understanding on how to support, encourage and educate women to manage their condition more effectively. Long term this could potentially improve pregnancy outcome, helping to reduce the future risk of type 2 diabetes in this population and subsequently pressure on healthcare systems. The aim of this study is therefore to explore the concerns, needs and knowledge of women diagnosed with GDM.

\section{Research design and methods}

This qualitative study used focus group methodology, to encourage the generation of ideas and expression of shared experiences and common viewpoints within a group of peers. Eligible participants were identified by the Diabetes Care Team at three National Health Service (NHS) hospitals in the United Kingdom. Women were given an invitation letter at a routine clinic appointment, and those interested in participating completed a permission slip, which allowed the researcher to contact them, and invite them to attend a focus group. Women aged 18-45 years and currently pregnant with GDM, or with a history of GDM in a recent pregnancy (up to 12 months post-natal) were eligible to participate. Those unable to adequately understand verbal explanations in English or who had special communication needs were excluded.

Eighty-one women expressed an interest in attending a focus group. Sessions were scheduled at various times and venues in an attempt to suit women and their working and family lives. From this number 38 were enrolled on the study. The remaining women who had expressed an interest in participating were either not able to make it to the scheduled focus group or were no longer contactable. Of the 38 enrolled, five were unwell or in hospital on the day, two delivered before the scheduled session and twelve did not attend the focus group. 


\section{ACCEPTED MANUSCRIPT}

Nineteen women took part in five focus groups (comprising of 2-7 women in each) between February 2012 and July 2012. Data saturation was reached after four groups, with the fifth focus group conducted to validate this finding. Women provided informed consent, completed a short demographic and pregnancy questionnaire, were introduced to one another, and were then asked a series of open-ended questions. Each session lasted between 45-75 minutes. Each participant was given a published guide on Diabetes and Pregnancy (Diabetes UK, 2013) and were invited to speak to a member of the Diabetes Care Team regarding any issues raised in the session. Women received a $£ 15.00$ gift voucher as a thank you for their time and to cover travelling expenses.

\section{Focus group discussion topics}

The following topic areas were discussed with the women: 1) current knowledge of GDM;2) anxiety following the diagnosis of GDM, and whether this changed overtime; 3 ) understanding and managing GDM and 4) the future impact of GDM.

\section{Descriptive qualitative analyses}

Focus groups were professionally transcribed verbatim, cross-referenced by the researcher and analysed by hand. Data analysis was undertaken using a conventional content analysis approach , as described by Morse and Field (1996) where the goal of the analysis was subjectively interpret the data through a systematic classification process of coding and identifying themes or pattern (Hsieh and Shannon 2005). Preconceived categories were avoided and categories flowed from the data. Initially the transcripts were read and re-read by three authors (CRD, VAH and FA), highlighting segments of data which were coded by identifying persistent words, phrases, themes or concepts (Morse, 1995). Data were then grouped according to topic, allowing further identification of sub-themes. Following coding, the data were categorised to reflect the overall sense of the data and the relationships between 


\section{ACCEPTED MANUSCRIPT}

the categories. Related categories were merged into themes. The themes were then discussed and compared among the researchers to verify accuracy of the codes.

\section{Findings}

\section{Demographics}

Participant characteristics are shown in Table 1. Women were aged 29-43yrs, of which $47 \%$ were white, $68 \%$ were currently pregnant, while the others were postnatal. Nulliparous women made up $32 \%$ of the group, while $32 \%$ had a diagnosis in a previous pregnancy. In total $58 \%$ required insulin during their pregnancy.

\section{Focus group themes}

Content analysis from the focus groups identified five themes: dealing with the diagnosis of GDM; adapting to blood glucose monitoring and medication to treat GDM; having adequate support, challenges associated with lifestyle change and, finally, consequences of having GDM. There was some overlap observed between the themes, however for simplicity they are presented separately.

\section{Dealing with the diagnosis of GDM}

Across all the groups, women reflected on being upset and feeling scared when diagnosed with GDM. Many blamed themselves and felt "guilty" for the development of the condition.

'Because I remember that weekend, talking to my husband, and being in tears, thinking is it something I've done, have I harmed our baby, have I sentenced this baby to have diabetes now as well for the rest of its life, and all those... all those things.' (Focus group 4; woman 2) 


\section{ACCEPTED MANUSCRIPT}

Some women blamed others for the development of the condition, highlighting their

ethnicity, family history of GDM or type 2 diabetes as the main cause. Although the majority did realise that being overweight was a risk factor for GDM, some expressed anger at not being told to lose weight prior to conception by a health professional.

'I was very, very cautious about every pregnancy, like going back to the doctor's every time it was over, then when I planned to start a new pregnancy, you know, how I ticked off all the boxes on everything I need to do ....but I still feel a bit let down. I felt that weight was something that... you know... picking up all the risk factors, and me doing my part going to the doctor or the midwife, and trying to get them to check whether I am okay, they should have... ...picked up on that weight issue too because, now, I realise that, pre-pregnancy, my BMI was on the higher side, and now I feel, it's still a thought, that maybe, if I wasn't, you know, overweight, and I was supposed to be in the level that I should, em, you know, I could have escaped it.' (Focus group 3; patient 4)

The diagnostic criteria for GDM were discussed in three focus groups. This caused frustration with many feeling they were being 'labelled' with a condition they were in denial of having, or that after being told their condition was 'borderline' feeling treatment was unnecessary. '...I was so confused because I thought...one person's telling me I don't [have GDM], the next person's telling me I do, the next person's saying, oh, it's borderline... and I'm like...I'm stuck in the middle here - where am I?!' (Focus group 1; woman 3)

\section{The challenges of blood glucose monitoring and use of medication to treat GDM}

All women agreed that blood glucose monitoring was time consuming and disrupted their daily routine particularly if working full-time. 


\section{ACCEPTED MANUSCRIPT}

'It's just obviously you feel quite restricted. It's not, you know...it's seven times a day you're doing it, and then, if you're taking insulin on top of that, it's...because it's all completely new, it's just trying to remember...'(Focus group1; patient 5)

'Well, I was a teacher, and I found like you have to eat at a certain time, you have to check at a certain time, check your levels at certain times, and sitting in a classroom full of kids, it's not easy to do.' (Focus group 4; woman 1)

Some women admitted to 'lying' or 'cheating' when recording their blood glucose reading in monitoring diaries, The reasoning behind this appeared to be two-fold: self-denial of having GDM and avoidance of being prescribed medication, particularly insulin.

'I must confess, em, I was living in self-denial, so most of the time, in my diaries, I would lie about my blood sugars. If it was, say, 10 point whatever, I'd just lie-.... ...I think it's just that path of self-denial, thinking to yourself, no, it can't be happening to you, so you kind of make it up sometimes.' (Focus group 3; woman 3)

Being prescribed medication, in particular insulin caused a great deal of anxiety and again many felt 'a failure' when told it was necessary to manage their condition. Others also believed they now had 'diabetes for life'. Alarmingly, some women described starving themselves as they thought this was the best way to control their blood glucose levels.

'......I had to be coerced to add insulin to my medication [laughing], which I...initially didn't want to go because I was...I had this preconceived mind set that once you go on insulin, then you become a confirmed diabetic, so I said, no, no, declined it like 400 times. They had to 


\section{ACCEPTED MANUSCRIPT}

bring several consultants to speak to me, and eventually, I did agree to go on it. It was a good thing I did, because as soon as I got on the insulin, it helped my blood sugar, and the baby obviously is...normal size, not too big.'(Focus group 3; patient 3)

'....I was so distraught, I stopped eating completely, ....... I was almost passing out, and em...didn't know what was wrong with me, rushed to the GP and ... ..... And I remember her words today [laughing], she was so cross with me! "What are you doing to yourself?!” I said, "Well, my blood sugars were so high, so I refused to eat." She said, "Well, you're just going to kill yourself, just going to drop dead, and nobody will know what happened to youyou need to still look after yourself!" (Focus group 3; woman 3)

Among the groups with mixed ethnicity, the use of herbal remedies as an alternative to insulin was discussed, particularly in those from an Asian background. Use of these products seemed to originate from different cultural beliefs, and the idea that GDM could be controlled with 'natural' remedies.

'I don't know if anybody tried anything different.....I looked at herbal remedies because that's something that [laughing], you know, you think is quite safe.....I didn't want to go on any medication at that point. So, I don't know if you've heard of fenugreek seeds? That's something that I read very much about and I thought, wow, you know, this is going to work, no insulin, nothing, and it's going to get my blood sugars down....... so I did that for a few days, but I began to read about it, and then it said that pregnant women shouldn't eat fenugreek because it initiates contractions [gasps]!' (Focus group 3; patient 4) 


\section{ACCEPTED MANUSCRIPT}

'I've got a next door lady, she's got diabetes... when I was telling her I was diagnosed...she brought me cinnamon sticks, and I thought...why [laughing], and then she goes - she started making it around my house, and I felt kind of awkward that she's taking over my kitchen and then... because she couldn't speakfluent English properly, so which made it very hard, but instead, she showed me how to do it, and I thought, you know what, you're a miracle worker.'(Focus group 3; patient 1)

\section{Having adequate support}

Family and friends provided positive support throughout pregnancy and in the early postnatal period. This was particularly important when the women suffered from other pregnancy aliments and did not feel well enough to eat or adequately monitor and control their diabetes.

'Because I suffer from migraine, it is very difficult, ......Because, yesterday, I was sleeping the whole day. ...... my husband tried to wake me up.... he pricked my fingers and he did the blood sugars because I wasn't doing it, and then he goes, "You're going into hypo,- you need to eat something," and I go, "Just give me a tablet, give me a sweet, and I'll suck it and go to sleep," because it was that bad...'(Focus group 3; woman 1)

'Well, I wouldn't have done it without my partner like because he was like, "Up, eat now, insulin," you know, and I would be, "Yeah, I'm going to get up in 20 minutes and I'm going to do this," and he was like, "Now, eat, your insulin," you know. He's the only person.' (Focus group 1, woman 1)

'Yeah, yeah. With me, I'm very, very grateful that I have him. So, since he knows that I'm on this diet, it's like everybody in the house is doing it together-more fruit in my house. So, 


\section{ACCEPTED MANUSCRIPT}

he's really helpful. He knows that because, eh, if I'm pregnant, like someone is eating, Ifeel like eating. So, because of that, he tried not to buy something sugary or trying to make something that would be good for everybody, because I might be tempted to...'(Focus group 2, woman 1)

\section{Challenges associated with lifestyle change}

Many found the changes they were required to make to their diets difficult, particularly those women from Asian and Black African ethnicity as their cultural diets tended to be 'carbohydrate heavy'. Some women from different ethnic backgrounds felt that the time with the dietician was limited, not personalised enough and that dietary advice was too 'westernised'. They expressed a desire to speak with someone who was more familiar with their cultural diet.

I remember when I first met the nutritionist. I was trying to describe a yam to her - she didn't know what it was. So, I said, when I come in for my next appointment, I'll bring a yam to show you what it is, because, you know, I was trying to describe, this is what we eat,' (Focus group 2; woman 1)

'the diet advice that you get. In my case, I felt that em...it was difficult to sort of stick to that because I'm not like a cereal person every morning. My diet is very much South Indian in origin, and South Indians are very good at having rice dishes, right from morning........ And then lunch also, you have rice and curry, and evening as well...... and it's very hard sometimes to cook...cook twice - for your husband, something, you know, different, for yourself.' (Focus group 4; patient 3) 


\section{ACCEPTED MANUSCRIPT}

'So, when she explained to me that I could have protein, fish, meat, I tried it, but, because, over the years, ...I must have a carbohydrate meal in a day-if not, I don't feel full....its habits over the years ... especially those of us from the Asian/African background, to consciously, you know, cut down. Ijust...that's the most difficult thing for me, because, every time, em, I go to see my consultant, and he says, "Do you want to see the nutritionist?" and I go, "No," and he goes, "Why?" and I just explain...it's not good, it's not working, because, no matter what she tells me, when I go back home, they're not practical. We're not salad, salad kind of people.' (Focus group 3; woman 3)

Controlling blood glucose levels after eating fruit was difficult for many women. Most found it confusing and frustrating that they could only eat a very small portion at once, or could not eat particular fruits at all which they enjoyed prior to being diagnosed with GDM

'The thing that I found confusing is about possible fruits. Because the first time that I went... they told me you...you can eat any fruit. And then I had an appointment with ........ the GP,. So, I told him that I was eating banana. He told me, no, banana is so bad, you cannot eat that, so I was...I got confused because I had received two different messages: like, any fruit is good, and then, no, you cannot eat bananas, so I was confused.....' (Focus group 2; woman 2)

Although the majority of women were determined to make the necessary changes to their regular diet to control their blood glucose levels adequately, many found it difficult to resist temptations and cravings, particularly when eating out or with family and friends. Moreover, they became 'bored' with their diet over time and missed having a lack of variety. 


\section{ACCEPTED MANUSCRIPT}

'I'd go to my Mum's house for Sunday dinner, and there's always a ton of sweets, and it was like...it was torture...... and before you know it, you've had a whole portion and a half, or two.' (Focus group 5; woman 2)

All women realised the benefits of physical activity in controlling their blood glucose levels and for the future prevention of type 2 diabetes. However, many found it difficult to fit this into their daily routines and discussed barriers such as tiredness, laziness, time constraints or other priorities or other physical constraints of pregnancy such as backache or swollen legs.

'There is another problem with me also, that I am having big back pain. It's too much that, sometimes, it's very hard for me to move, ....So, thinking about exercise is very hard for me. (Focus group 3; woman 5)

\section{Consequences of having GDM}

Not all were aware of the potential consequences having GDM could have on their delivery and baby post-partum. In relation to the longer term implications of having GDM, only a few women were aware that they would have an increased risk of developing type 2 diabetes in the future, and being diagnosed with GDM in subsequent pregnancies.

'Finding out everything, the consequences then of ...of what the diabetes would actually mean for the child birth and things like that.... That would be good to know and to understand.....,'(Focus group 5; woman1)

\section{Discussion}

\section{Summary of Main Findings}




\section{ACCEPTED MANUSCRIPT}

Women experience a steep learning curve from time of diagnosis to delivery of their baby.

This was evident in changes to attitudes and anxieties over time, finally leading to acceptance of the condition and best management. Nulliparous women and those who had an uncomplicated pregnancy until GDM diagnosis experienced similar emotions of shock and anxiety. Interestingly, some women expressed anger at their HCP's for not advising them to lose weight prior to conception, even though they had sought advice on their health. This is a sensitive topic for HCP's to initiate, but addressing this subject should become routine in preconception care, considering the escalating diagnosis of GDM and type 2 diabetes. There was also frustration over the different diagnostic criteria used between hospitals. Women whose condition was deemed as "borderline" felt they did not need to attend specialist antenatal care and that they were being 'labelled' with a condition that they did not really have.

When first diagnosed all women found blood glucose monitoring difficult, time-consuming and disruptive of their daily routine, particularly those who worked full-time. However after a period of 'trial and error' they were able to keep within the recommended blood glucose targets. A few women reported 'lying' about their blood glucose readings to the diabetes care team and others "starving" themselves. This reflected a lack of understanding of the condition as well as self-denial and fear of being prescribed insulin.

Support from family and friends was appreciated but these women felt that it was difficult to explain the condition, and suitable educational resources were limited or of poor quality. Many feared becoming a social stigma. Women then resorted to the internet or family and friends for advice. Incorrect, non-evidenced based advice on how to manage GDM from well-meaning family and friends ranged from eating particular foods which were perceived as healthy and the use of herbal medicine instead of insulin. Many difficulties with dietary change were identified, with the most prominent being how to adapt ethnic diets. Establishing 


\section{ACCEPTED MANUSCRIPT}

a regular routine for eating/changing eating habits and, difficulties with understanding the

rules around eating fruit were also discussed. Not all women were aware of the short or longterm implications of having GDM, and very little time was spent discussing this. In the majority of the focus groups, this topic had to be prompted by the facilitator.

\section{Interpretation of Findings}

Previous studies have reported that it is common for women to feel shock, anxiety and fear at the time of diagnosis (Tait Neufeld, 2011, Persson et al.2010); even if they were aware of the risk factors for GDM. Evans \& O’Brien (2005) and Hjelm (2005) suggested women felt morally compelled to adhere to the regime recommended by their HCP believing it was their fault their baby's well-being was at risk and Lawson \& Rajaram (1994) described women feeling like failures after being diagnosed with GDM. This highlights that members of the multidisciplinary diabetes care team need to be aware of the impact of GDM diagnosis on the individual and need to take the opportunity to educate and reassure the woman regarding treatment decisions and lifestyle choices in order to prevent possible anxiety and noncompliance. This would also apply to those women who perceived that they were diagnosed as 'borderline GDM' which was probably the result of hospitals not uniformly using the IADPSG diagnostic criteria. Whilst not subsequently adopted by NICE guidelines, the IADPSG diagnostic criteria recommendation, was under debate at the time of this study (Meek et al.2015).

Overtime most women became more confident at effectively managing the condition and they felt a sense of empowerment and self-efficacy. This has been described elsewhere as 'from stun to gradual balance'(Persson et al.2010) meaning women become familiar with their diabetes and have a greater ability to cope with the associated stress as treatment became part of their daily routine(Persson et al.2010,Lawson \& Rajaram, 1994) . Non- 


\section{ACCEPTED MANUSCRIPT}

compliance was also reported; with a few women cheating on their diet and recording false blood glucose readings. This behaviour has been previously reported by Tait Neufeld (2011) and appears to be most common when women are part of a social gathering (Evans \& O’Brien, 2005). More worryingly, some women admitted starving themselves in an attempt to control their blood glucose and avoid being prescribed insulin. Similarly, the study of aboriginal women by Tait Neufeld (2011) observed that women were so concerned about their baby's health and control of their blood glucose levels that they drastically limited their food intake to protect the baby.

Being prescribed insulin seemed to increase the perception of severity of the condition for the women in our population, similar to the women in Persson et al. (2010) who described the progression to insulin as a constant threat, resulting in anxiety and fear returning, comparable to when first diagnosed. However, it was reassuring that those prescribed insulin reported feeling better on the regime, Bandyopadhyay et al. (2011) reported similar findings. This cycle of emotions identifies an area of education which needs to be strengthened. It is important for members of the multidisciplinary diabetes care team to reassure women and their families that insulin treatment is not their fault, and that treatment will help rather than harm their unborn baby.

When discussing the support of family and friends, it was clear that some women feared becoming a social stigma (Lawson \& Rajaram, 1994), particularly women from different ethnic backgrounds. Family mealtimes are important in many cultures, and as many ethnic diets are particularly carbohydrate-heavy, women continued to cook (and eat) the traditional meals for the family and were reluctant to be a nuisance, and hence also felt obliged to eat food which was prepared for them, similar findings have been reported in Persson et al.2010, Razee et al.2010 \& Evans \& O'Brien, 2005. We and others (Tait Neufeld, 2014, Lawson \& 


\section{ACCEPTED MANUSCRIPT}

Rajaram, 1994) report mixed responses about the support provided from HCPs. While women were extremely grateful for the advice throughout their pregnancy, some felt that advice was not individualised or suitable for their ethnicity, particularly in terms of dietary advice (Bandyopadhyay et al.2011). Some also reported that HCPs were unsympathetic at the time of diagnosis, and they simply stated the facts and recommendations as necessary, and did not take into consideration their emotional state (Lawson \& Rajaram, 1994). Careful consideration of a woman's background and needs is vital to avoid them feeling patronised or alienated. An example of this was highlighted by Tait Neufeld (2014) when a woman stated that the dietician 'made them feel like a child because she had plastic apples and bananas'. Bennett et al. (2011) found that women were more inclined to attend appointments if they had developed positive relationships with their multidisciplinary diabetes care team.

The lack of suitable and available high quality information was reported by this group and others (Collier et al.2011, Ruggiero et al.1990), with women describing how they were provided with a poorly photocopied leaflet, which usually ended up in the bin. This situation has been previously reported and found to cause stress and confusion (Tait Neufeld, 2014) and highlights the need for high-quality educational resources. The aim of such resources would be to create greater support for women and their families, aiding compliance with recommendations from HCP's (Mersereau et al.2011). Women's lack of awareness of the short and long term impact of GDM may reflect that their focus remains on maintaining a "healthy" pregnancy and post-delivery their concern is for their baby's health rather than their own and they no longer need to agonise over what food they consumed (Tait Neufeld,2011) . Kim et al. (2007) measured risk perception in women with a history of GDM and although $90 \%$ recognised GDM as a risk factor for developing diabetes only $16 \%$ believed they were at high risk, increasing to $39 \%$ when asked to reflect on their lifestyle. This stresses the importance of the role of HCP's in emphasising the long-term change to a 


\section{ACCEPTED MANUSCRIPT}

healthier lifestyle for the prevention of type 2 diabetes and GDM in subsequent pregnancies.

These discussions may currently be reserved for the postnatal OGTT check-up. However, given that a large proportion of women do not attend this appointment for various reasons (Bennett et al.2011, Nielson et al.2014) it is important for HCPs to discuss long-term risk at the initial diagnosis. This is the one time when the multidisciplinary diabetes care team has a rare opportunity to alter the natural course of disease and change the future health of women (Bentley-Lewis, 2009).

\section{Strengths and limitations}

The multi-centre and multi-ethnic design of this study was a major strength of this research. A collection of extensive views and experiences pre and post pregnancy were confirmed as participants varied in age, mix of parity, first time diagnosis of GDM or previous experience of the condition, with a variety of treatment regimes used. The focus groups functioned well as there was instant rapport among the women who participated as they had something in common which ensured that they spoke openly about their knowledge and experiences. This openness was also enhanced as the groups were co-ordinated by an individual, who was independent of the women's care team. However, the sessions were restricted to those who could speak English, as the use of interpreters would have affected the natural flow of conversation.

The education status of some of the groups seemed high, and some of the numbers in individual sessions were small. While there was interest in participating, recruitment of this group was difficult. Women were reluctant to attend another appointment, as they were reviewed so frequently throughout their pregnancy. Many were working and /or had no childcare available. One consequence of recruitment difficulty was the necessity to run a focus group with just two participants which, while perhaps challenging the principles of 


\section{ACCEPTED MANUSCRIPT}

focus groups, still allowed us to engage with women to explore their needs and knowledge.

Despite this, the study reached data saturation, as the same topics were being revisited.

\section{Conclusion}

In conclusion, this qualitative research in a multicentre, multi-ethnic group provided rich data on the current knowledge, anxiety and attitudes of women with gestational diabetes. The research highlights a need for advice from the multidisciplinary diabetes care team a to be more individualised, and culturally appropriate, particularly regarding diet. Lack of availability of reliable high quality information, in a user-friendly format was also highlighted. These factors can lead to feelings of uncertainty, as the woman does not fully understand the impact of her diagnosis. Consequently, if the woman is able to manage her condition more effectively by improving communication through the provision of personalised support and information, this could help enhance her experience of pregnancy and childbirth and influence a change in positive lifestyle choices for her future health.

\section{Disclosure of interests}

The authors report no conflict of interest

\section{Contribution to authorship}

VH, RH, DRM, MM and FA conceived and designed the research. CD \& VH carried out the focus groups. VH, CD, FA \& OM analysed and interpreted the data. CD drafted the article. All authors edited and revised the article

\section{Details of ethics approval}

Ethical approval was sought and granted by the Office of Research Ethics for Northern Ireland in 2011, research number (11/NI/0158). 


\section{Funding}

This project is supported by BRIDGES. BRIDGES is an International Diabetes Federation programme supported by an educational grant from Lilly Diabetes (LT10-346).

\section{Acknowledgements}

The authors would like to thank the women who consented to participate in the research for their time and invaluable contribution. We are grateful to the staff in Belfast Health and Social Care Trust, South Eastern Health and Social Care Trust and Central Manchester University Hospitals who supported and helped to facilitate the research.

\section{References}

Bandyopadhyay M, Small R, Davey MA, Oats JJ, Foster DA\& Aylward A (2011) Lived experience of gestational diabetes mellitus among immigrant South Asian women in Australia. The Australian and New Zealand Journal of Obstetrics \& Gynaecology 51(4) 360364. doi: 10.1111/j.1479-828X.2011.01322.x.

Bellamy L, Casas JP, Hingorani AD \& Williams D (2009) Type 2 diabetes mellitus after gestational diabetes: a systematic review and meta-analysis. Lancet 373, 1773-1779. doi: 10.1016/S0140-6736(09)60731-5.

Bennett WL, Ennen CS, Carrese JA.Hill-Briggs F,Levine DM, Nicholson WK \& Clark JM (2011) Barriers to and facilitators of postpartum follow-up care in women with recent 


\section{ACCEPTED MANUSCRIPT}

gestational diabetes mellitus: a qualitative study. Journal of Women's Health (Larchmt) 20

(2) 239-245. doi: 10.1089/jwh.2010.2233.

Bentley-Lewis R (2009) Gestational diabetes mellitus: an opportunity of a lifetime. Lancet 373 (9677) 1738-1740. doi: 10.1016/S0140-6736(09)60958-2.

Collier SA, Mulholland C, Williams J,Mersereau P, Turay K \& Prue C (2011) A qualitative study of perceived barriers to management of diabetes among women with a history of diabetes during pregnancy. Journal of Women's Health (Larchmt) 20 (9)1333-1339. doi: 10.1089/jwh.2010.2676.

Daniells S, Grenyer BF, Davis WS, Coleman KJ, Burgess JA \& Moses RG (2003)

Gestational diabetes mellitus: is a diagnosis associated with an increase in maternal anxiety and stress in the short and intermediate term? Diabetes Care 26, 385-389.

DeSisto CL, Kim SY, Sharma AJ (2014) Prevalence Estimates of Gestational Diabetes Mellitus in the United States, Pregnancy Risk Assessment Monitoring System (PRAMS), 2007-2010. Preventing Chronic Disease 11:130415. DOI:

http://dx.doi.org/10.5888/pcd11.130415㤀.

Diabetes UK (2008) Pregnancy and Diabetes. London: Diabetes UK.

Evans MK \& O'Brien B (2005) Gestational diabetes: the meaning of an at-risk pregnancy. Qualitative Health Research 15 (1) 66-81.

Hsieh and Shannon (2005) Three approaches to qualitative content analysis. Qualitative Health Research 15 (9) 1277-1288. doi: 10.1177/1049732305276687 


\section{ACCEPTED MANUSCRIPT}

Hjelm K, Bard K, Nyberg P \& Apelgvist J (2005) Swedish and Middle-Eastern-born women's beliefs about gestational diabetes. Midwifery 21 (1) 44-60.

Jiwani A, Marseille E, Lohse N, Damm P, Hod M, Kahn J (2012) Gestational diabetes mellitus: results from a survey of country prevalence and practices. Journal of Maternal Fetal \& Neonatal Medicine 25(6):600-10. doi: 10.3109/14767058.2011.587921.

Kim C, McEwen LN, Piette JD, Goewey J, Ferrara A, Walker EA (2007) Risk perception for diabetes among women with histories of gestational diabetes mellitus. Diabetes Care 30(9):2281-2286.

Lawson E, Jean \& Rajaram, Shireen (1994) A transformed pregnancy: the psychosocial consequences of gestational diabetes. Sociology of Health and Illness 16 (4), 536-562. DOI: 10.1111/1467-9566.ep11347644

Meek CL, Lewis HB, Patient C, Murphy H \& Simmons D (2015) Diagnosis of Gestational diabetes Mellitus: Falling through the net. Diabetlogica 58 (9) 2003-12 DOI 10.1007/s00125$015-3647-\mathrm{z}$

Mersereau P, Williams J, Collier SA, Mulholland C, Turay K \& Prue C (2011) Barriers to managing diabetes during pregnancy: the perceptions of health care practitioners. Birth 38, 142-149. doi: 10.1111/j.1523-536X.2010.00464.x.

Metzger BE, Gabbe SG, Persson B, Buchanan TA, Catalano PA, et al. International association of diabetes and pregnancy study groups recommendations on the diagnosis and classification of hyperglycemia in pregnancy. Diabetes Care. 2010 Mar;33(3):676-82.

Morse JM (1995) Qualitative Research Methods for Health Professionals. London, UK: Sage Publications 


\section{ACCEPTED MANUSCRIPT}

Morse JM \& Field PA (1996) Nursing Research: The Applications of Qualitative

Approaches. 2nd ed. Chapman \& Hall.

National Institute for Healthcare and Excellence (2015) Diabetes in pregnancy: Management from pre-conception to the postnatal period. https://www.nice.org.uk/guidance/ng3

Nielsen KK, Kapur A, Damm P, de Courten M \& Byqbjerg IC (2014) From screening to postpartum follow-up - the determinants and barriers for gestational diabetes mellitus (GDM) services, a systematic review. BMC Pregnancy and Childbirth 14, 41-2393-14-41. doi: 10.1186/1471-2393-14-41.

Persson M, Winkvist A, Mogren I (2010) 'From stun to gradual balance'--women's experiences of living with gestational diabetes mellitus. Scandinavian Journal of Caring Science 24, 454-462. doi: 10.1111/j.1471-6712.2009.00735.x.

Razee H, van der Ploeg HP, Blignault I ,Smith BJ, Bauman AE,Mcclean M \& Wah Cheung N (2010) Beliefs, barriers, social support, and environmental influences related to diabetes risk behaviours among women with a history of gestational diabetes. Health Promotion Journal of Australia 21 (2) 130-137.

Ruggiero L, Spirito A, Bond A,Coustan D \& McGarvey S (1990) Impact of social support and stress on compliance in women with gestational diabetes. Diabetes Care 13 (4) 441-443.

Tait Neufeld, H (2011) Food perceptions and concerns of aboriginal women coping with gestational diabetes in Winnipeg, Manitoba. Journal of Nutrition Education \& Behaviour 43, 482-491. doi: 10.1016/j.jneb.2011.05.017. 


\section{ACCEPTED MANUSCRIPT}

Tait Neufeld, H (2014) Patient and caregiver perspectives of health provision practices for

First Nations and Metis women with gestational diabetes mellitus accessing care in

Winnipeg, Manitoba. BMC Health Services Research 14, 440-6963-14-440.

doi:10.1186/1472-6963-14-440.

Table 1: Characteristics of focus group participants $(n=19)$

\begin{tabular}{ll}
\hline Age (years) & $29-43$ \\
Range & $34.5(4.3)$ \\
Mean (SD) & $13(68)$ \\
& $6(32)$ \\
Pregnant with GDM & $6(32)$ \\
Postnatal with previous GDM & $11(58)$ \\
Nulliparous & \\
Insulin treatment & \\
& $9(47)$ \\
Ethnicity & $3(16)$ \\
White & $3(16)$ \\
Black African & $2(11)$ \\
Pakistani & $1(5)$ \\
Latin American & $1(5)$ \\
Bangladeshi & \\
Indian & \\
BMI (kg/m ${ }^{2}$ * & $27.3(6.9)$ \\
Mean (SD) & $20.8-48.8$ \\
Range & Data are $n(\%)$ unless otherwise stated. GDM is gestational diabetes Mellitus. BMI is body mass \\
index. *BMI only available for 16 women
\end{tabular}

